\title{
The Future Of Business: Merit In Writing Across The Curriculum
}

Heather Dana, Kaplan University, USA

Carol Hancock, Kaplan University, USA

JoDee Phillips, Kaplan University, USA

\begin{abstract}
As a direct response to higher education's challenge to produce more engineers, scientists, and business professionals, universities have increased the numbers of degrees and continue to focus on increasing the numbers of students in these areas. As recently as the 2011 State of the Union speech by President Obama, the United States is posed to increase federal and state grants which favor offering resources to these disciplines. This study will show that students improve their writing and communication skills by practicing them in their entire Associate or entire Bachelor program, and these skills can transfer into their professional lives.
\end{abstract}

Keywords: Writing; Writing Across the Curriculum

\section{INTRODUCTION}

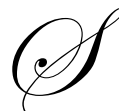

tudents live in an information and knowledge management economy in which the dissemination and analysis of information requires intellectual, technical and interpersonal skills. However, despite this focus on the development of hard skills, research from the private and the public sector in both academics and workplaces indicates that the lack of soft skills among our college graduates is alarming. Both the public and private sectors seek and require these soft skills in their current employees and new hires, yet both find such skills to be lacking and that deficit costs them potential profits.

Soft skills are thought of, for the most part, as communication skills, critical thinking, reasoning, problem solving, and written communication. One of the biggest misconceptions about many soft skills is that students can learn them in an English course and simply have them in their bank of knowledge. However, all of these skills are learned through practice over time. Writing across the Curriculum (WAC) is a long standing educational movement that seeks to improve students' critical thinking, analytical, and writing skills by integrating writing instruction throughout all disciplines and courses, and throughout a student's entire college course work. This study completed at an online university will be undertaken to show that students improve their writing and communication skills by practicing them in their entire Associate or entire Bachelor program, and these skills can transfer into their professional lives.

A misconception is that students by osmosis should know how to write for the workplace because they have learned to write in school. In fact, most of the writing instruction in this online university is geared toward teaching students to write within the first year English course. Coupled with that, the skills students learn by writing academic papers do not necessarily transfer to the ability to write workplace documents. Issues of purpose, audience, context, diversity and ethics change significantly from academia to the workplace. Students often enter the workplace without any significant sense of the communication, interpersonal, and intellectual demands of the workplace environment. Students, who understand something intellectually through reading, discussing, and testing, should be able to apply that understanding to their own workplace behavior. As an analogy, learning about the 4 Ps of Marketing (product, place, price and promotion) does not teach one to be a successful marketer. To become successful in one's career, students need not only learn the techniques, strategies, and vocabulary of their major, they need to understand that soft skills often are what make the difference between being hired, being promoted, and being successful in any profession. Students tend to avoid courses in writing and communication, and unfortunately 
the curriculum of many universities does not require such coursework beyond general education requirements.

Students who have had the English composition course required of college freshman not only have difficulty transferring what they have learned to the workplace, but they also have less than adequate skills needed for writing at work and it is arguable that even the best students in all disciplines have significant difficulty transferring writing skills from their academics to their workplaces. How, then, can students transfer their writing knowledge from their academic disciplines to the workplace? This online university believes that a first step is to perceive the learning of writing as an incremental series of building knowledge and assessment of writing skills as a part of each course. This developmental model of using Writing across the Curriculum for training students in disciplined based writing can help students prepare better for the workplace. Most students are prepared to work hard if they perceive a useful reason for doing so. Incorporating and reinforcing how much writing there is in the workplace and how much more money students are likely to make over the length of their careers by becoming better writers creates a greater continuing consciousness, making the underlying assignment of Writing across the Curriculum invaluable to students.

The literature will show that employers place a great deal of emphasis on the writing skills of their employees. Knowing that it is imperative to encourage appropriate writing skills in courses, the question then becomes how a proper assessment of writing skills will ensure that students' writing scores are improving in this online university. This paper examines some of the methodology and processes for assessing college level writing outside the English classroom, and provides a recommendation for further research in this area.

\section{LITERATURE REVIEW}

Employers have ranked the writing abilities of their employees as among the most important qualifications for the job (Quible \& Griffin, 2007). However, employers are largely dissatisfied with the writing abilities of their employees. Academicians have recognized the problem, and have made numerous efforts to improve the writing abilities of college graduates. Regardless of those efforts, American companies spend about $\$ 3.1$ billion every year to "remediate employees' writing deficiencies" (p. 32).

Many factors contribute to poor writing skills among college graduates, and post-secondary educators have implemented a number of approaches to address the problem. One remediation is 'writing across the curriculum' (WAC) programs designed to incorporate writing in all college courses with the expectation that writing will improve with practice and appropriate feedback The WAC programs have generally been met with limited success (Betts \& McCarthy, 2010). However, writing within the context of a given course along with active help from instructors has proven to be more successful than students using a writing center where the instructors are not directly involved (Betts \& McCarthy).

One reason context based and professor supervised writing practice enjoys some success might be that grammar and punctuation is best learned when feedback is given on a particular writing assignment. Many academicians believe this approach is far superior to the rules based approach that was popular in the mid 1900s classroom. Though a context based approach to writing instruction is deemed important in the college-level experience, faculty members' still rate students' grammatical abilities as very important when entering college. Unfortunately, high school teachers commonly consider grammatical abilities to be one of the least important writing skills. The disconnect between high school teachers' views and college faculty expectations might account for the $20 \%$ of students who must take remedial writing courses in college (Quible \& Griffin, 2007).

Though there is a great deal of concern that students' writing abilities have declined in recent years, national assessments have not supported that thesis. The reality is that the portion of students with strong writing abilities has held relatively constant over the last 25 years. The reason academicians have noticed a downward trend in students' writing abilities when entering higher education is that a far higher number of high school graduates are attempting college (Jameson, 2007). National assessments have shown that about $25 \%$ of high school seniors have the writing ability to sustain successful efforts in college, yet a full two thirds are attempting college level work after high school (Jameson). Further exacerbating the problem is that SAT scores were 'recentered' in the 1990s, meaning that though the average SAT scores were dropping precipitously between the early $60 \mathrm{~s}$ and the early $80 \mathrm{~s}$, 
the College Entrance Examination Board (CEEB) that administered the exams recalculated the average scores and corrected them upward by about 80 points. That means that a prior score of 430 would now be reported as 530 (Jameson). The downward trend in scores over the identified 20 years was partially due to a broader test base (demographics), and partially due to actual lowered performance. The bottom line is that students with weaker skills are entering college because it is far more accessible. The popular rise of proprietary education has increased this accessibility. More than ever, proprietary schools have attracted non-traditional student populations (Apollo Group, 2010) because they often offer open enrollment, more convenient hours for classes (many times online), and they cater to adult learners. These adult learners may have never expected to be college bound, and therefore did not take advantage of the college preparatory options in high school.

In addition to increased scores on college entrance exams, students have also experienced higher grade point averages (GPAs) between the 60s and this decade. "The percentage of college freshmen who had an A average in high school increased from 18\% in 1968 to $48 \%$ in 2004" (Jameson, 2007, p. 29). Because national test scores decreased over that same period, the data shows that the grades high school students received probably did not reflect skill mastery. The inflated grades may give students an unrealistic expectation that they have the ability to do college level work.

\section{INTRODUCTION OF THE PROBLEM}

English departments traditionally have been dedicated to providing instruction in writing. This commitment to excellence is increasingly more complex and more challenging due to the growing diversity of the student population, the increasing demand for developmental instruction, and the expanding skills requirements in the workplace. The acquisition of writing skills is fundamental to the success of college students if they are to achieve their academic and career goals. In addition, college faculty members are held publicly accountable for preparing their students for the changing needs and expectations of today's workplace. Therefore, making careful evaluations and determining priorities on behalf of students and the discipline requires an increased knowledge of an effective curriculum that is responsive to learners and workforce needs. An understanding of how each relates to the discipline, to higher education, and to external business trends is also important. Thus, to understand and practice writing in multiple disciplines today, Writing across the Curriculum programs need to be instituted and assessed if students are to be well served.

\section{BACKGROUND OF THE STUDY}

The authors of this paper wish to uncover the outcomes associated with integrating writing in all university courses. The WAC movement encourages the addition of writing to most courses for two principal purposes: students will learn the material better and this better understanding will lead to improved written communication. This paper will include a brief introduction to Writing across the Curriculum (WAC) as well as associated theory and practice. It will emphasize using writing as a tool for learning and assessing the discipline being studied, and as a strategy for improving the confidence and the ability of students to communicate effectively.

WAC has continued to grow in higher education, and this university has implemented WAC as a way to help improve the communication abilities of students. Several factors have led the university to this realization: national publicity about a literacy crisis, the advent of the information society, complaints from employers about college graduates who are technically very competent, but weak on communication skills, and a growing recognition that communication is an increasingly important and demanding aspect of work. WAC assignments are embedded in each course and are integral to the reflection of knowledge in that course.

\section{STATEMENT OF THE PROBLEM}

This study focuses on the problem that higher education institutions are in a unique position to respond to the changing needs of their diverse student populations and to prepare them for further academic studies, the workplace, and for living in a democratic society. Often academics feel that communication skills can be taught in a vacuum, independent of a person's knowledge of a particular subject or understanding in the context of the discipline. WAC addresses the issue of improving students' written communication abilities by stressing that 
learning to write effectively is dependent on the students' knowledge of the subject matter as well as their understanding of the social context for the writing. Thus, WAC has gained many supporters in all disciplines because academics see mastery of knowledge and its applications as central to becoming an effective practitioner and communicator within any discipline.

\section{RATIONALE}

The paradigm shift from a teaching-centered to a learning-centered classroom has challenged traditional methods of teaching writing. Current writing theory focuses attention on the writing process and the social context of language, emphasizing the importance of instruction for students so they gain the ability to write for a variety of purposes. Because the expectations of academic institutions and the workplace are constantly changing, systematic and ongoing assessment is essential to providing a responsive curriculum that prepares students for their academic and work environments. The National Commission on Writing appointed by the College Board determined that writing is an essential skill for all Americans (Bosley, n.d.). The first report, issued in 2003, "called for a writing agenda for the nation, promising to lead such a national agenda around writing." (p. 6) Three subsequent reports have been presented to Congress about the state of writing in U.S. schools, colleges, and workplaces (Bosley, n.d.). Senator Bob Kerry, President of the New School University in New York, and Chair of the National Commission stated "In a very real way neither our democracy nor our personal freedoms will survive unless we as citizens take the time and make the effort needed to learn how to write."(p.7)

\section{PURPOSE OF THE STUDY}

The purpose of the study is to determine if the introduction of writing in all courses in this online university has a positive effect on the mastery of student writing. Furthermore, how will these writing skills affect the jobs that these students obtain after graduation and in turn what will this do for the writing skills of the American workforce?

\section{SIGNIFICANCE OF THE STUDY}

The literature shows a lack of writing skills among workers today. The information gathered and analyzed by the authors in this study will help determine if WAC initiatives might help ensure better writing skills of college graduates. Three populations that will benefit from the study are faculty, students and administrators. Will writing skill measures improve and will employers see a positive change in writing skills of newly hired college graduates by implementing the use of Writing across the Curriculum in multiple academic disciplines and courses? This question is important to the populations involved and this study will focus on the process for answering those questions.

\section{RESEARCH HYPOTHESES}

1. Null Hypothesis (Ho1): There are no statistically significant changes in student writing quality from the first course to the last course in the university curriculum.

2. Alternative Hypothesis (Ha1): There are statistically significant changes in student writing quality from the first course to the last course in the university curriculum.

3. Null Hypothesis (Ho2): There were no statistically significant changes in student writing scores at this university with exposure to the WAC assignment.

4. Alternative Hypothesis (Ha2): There were statistically significant changes in student writing scores at this university with exposure to the WAC assignment.

\section{ASSUMPTIONS AND LIMITATIONS}

Weaknesses in this study may be related to the inadequate measures of variables, loss of students in the program, student transfers into the program, lack of valid data, small sample size, errors in measurement and other factors related to data collection with online students. The online university where data will be collected generally includes more diverse backgrounds of students than a campus university, thus the comparability of this study to on ground students would be diminished. With the focus of this study on the relationship between writing skills of 
students who have graded writing assignments in each course in their specific curriculum, the following assumptions were made regarding this study:

1. Thorough explanation of grading rubrics to faculty.

2. Thorough understanding of grading rubrics by students.

3. Consistent faculty member expectations of writing and use of rubrics.

4. The study accurately determines the level of relationships between the variables.

5. WAC scores accurately reflect the quality of student writing.

\section{METHOD}

The method that is used by the authors for the first hypothesis include an analysis of the change in scores on the standard writing assignment placed in each course of the curriculum. The authors will use data from a course at the beginning of the curriculum and compare the scores to a course at the end of the curriculum. The second hypothesis will address using the Capstone course in the online university. The authors will analyze the difference in writing scores from the first academic term the WAC assignment was added to the course to the WAC scores in the most recent term. The comparisons in both methods will determine if there is a relationship between the introduction of the writing assignments and student mastery of writing skills.

\section{RESEARCH FINDINGS AND DISCUSSION}

\section{Assumptions}

Most statistical tests rely upon assumptions about the variables used in the analysis. When these assumptions are not met, the results may not be dependable, resulting in a Type I or Type II error, or an over or underestimation of significance or effect size. Pedhazur (1997) observed, "Knowledge and understanding of the situations when violations of assumptions lead to serious biases, and when they are of little consequence, are essential to meaningful data analysis." (p. 33) However, few articles report having tested assumptions of the statistical tests they rely on for drawing their conclusions. This creates a situation in which these researchers have a rich literature base, but are forced to question the validity of many of the results, conclusions, and assertions, as they have no idea whether the assumptions of the statistical tests were met (Osborne, Christensen, and Gunter, 2001). These researchers believe that checking these assumptions carries significant benefits for the researcher, and by making sure an analysis meets the associated assumptions helps avoid Type I and II errors.

\section{Missing Data}

The default way of deleting missing data while calculating a correlation matrix is to exclude all cases that have missing data in at least one of the selected variables; that is, by case wise deletion of missing data (Field, 2009). However, if missing data are randomly distributed across cases, you one could easily end up with no valid cases in the data set, because each of them will have at least one missing data in some variable. The most common solution used in such instances is to use pair wise deletion of missing data in correlation matrices, where a correlation between each pair of variables is calculated from all cases that have valid data on those two variables (Field, 2009). In the data related to first term and capstone course data set, the option of pair wise was used so that any student who had a score missing for a variable, their data will be excluded only from calculations involving the variable for which they have no score.

\section{Findings}

The information in Table 1 represents measures of central tendency to summarize the data for the Writing Acoss the Curiculum assessment scores for first term students and captone students. Measures of dispersion were computed to understand the variability of scores for the WAC variable. The following are the results of this analysis; $\mathrm{N}=93, \mathrm{M}=4.04$ and 4.86; $\mathrm{SD}=.340$ and 1.173. When examining the mean for Student Writing Across the Curriculum(WAC), assessed scores for the capstone course is high. Therefore, it appears that most of the students were very close to mastery level; the students exhibited a strong higher order critical thinking in their evaluation and 
analysis. The standard deviation was small, relative to the value of the mean, indicating datapoints are close to the mean and students were in the proficient level indication on minor digressions in their critical thinking and analysis $(M=4.867, S D=.340503 ; N=93)$. However, the standard deviation for Student Writing Across the Curriculum(WAC) assessed scores for the first term course was larger, indicating more variance in their writing from a lower mean with assessed scored in the practiced and mastery level. The results indicate that students come to this university with varied writing skills, some exhibiting limited higher order chriting thinking and analysis, and some exhibiting stong higher order critical thinking skills. $(M=4.047, S D=1.173 ; N=93)$. The data reflects an increase in the students' writing scores $(M=4.04, M=4.86)$ of $20 \%(.20)$ from assessed score in the first term course to the capstone course.

The information in Table 2 represents measures of central tendency to summarize the data comparing five terms for students in the capstone $\operatorname{course}(M=4.375, M=5.0 ; N=8)$. The data reflects an increase in the asseessed scores of $14 \%(.14)$. The results indicate that there is a statistically significant difference between students' writing abilities after the WAC project began. In the first term, where students were not regularly assessed for their writing capabilities, their writing abilities were not as advanced. After an emphasis was placed on writing, and students had a longer exposure to that focus by the university, their writing improved, resulting in a rejection of the null.

Table 1

Descriptive Statistics of Student Scores for WAC for First Term Course and Capstone Course

\begin{tabular}{|l|c|c|c|}
\hline \multicolumn{3}{|c|}{ Descriptive Statistics } \\
\hline MT 299 & N & Mean & Std. Deviation \\
\hline CS 113 & 46 & 4.8696 & .34050 \\
\hline Valid N (listwise) & 46 & 4.0435 & 1.17296 \\
\hline
\end{tabular}

Table 2

Descriptive Statistics of Student Scores for WAC for First Term Course vs. Capstone Course for Five Terms

\begin{tabular}{|l|c|c|c|}
\hline \multicolumn{3}{|c|}{ Descriptive Statistics } \\
\hline Term 7 & N & Mean & Std. Deviation \\
\hline Term 12 & 8 & 4.3750 & .51755 \\
\hline Valid N (listwise) & 13 & 5.0000 & .00000 \\
\hline
\end{tabular}

\section{Discussion}

The findings suggest that the implementation of the WAC project at this university results in increased writing skills for its students.

Ho1 is rejected. The research findings suggest that there is a significant improvement in students' writing quality as they progress through the university curriculum from the first term course to the capstone. The university observed a significant variability in the quality of students' writing. The overall quality is lower when they first enroll in a course than observed at the end of the students' associate degree. Similarly, Ha1 is accepted because there appears to be a significant improvement is students' writing abilities as they progress through the university curriculum, and continue being assessed with the WAC assignment.

Ho2 is rejected. The research findings suggest that there is a significant improvement in students' writing skills with exposure to the WAC assignment. When assessing the WAC assignment when first implemented, student scores were significantly lower than after five terms of assessing this same assignment. This finding suggests that more attention to student writing may have resulted in better writing performance. Similarly, Ha2 is accepted because there appears to be a significant improvement in students' writing abilities after they had been exposed to the WAC assessment in a number of previous courses. 


\section{FUTURE RESEARCH OPPORTUNITIES}

Most of the communication and writing skills developed in college online universities tend to be more appropriate for online asynchronous discussion boards than for real world involvement and applicability.

Partnerships between employers through internships, business based simulations and projects as course assignments and other means should be examined and added into curriculum to better align the skills taught in academia with those skills needed in the workplace. The lack of informal writing in the majority of online classes at this university illustrates a deficient area in the curriculum. It may be beneficial to provide faculty course leads with examples of how informal writing is used in business classes at other universities has help incorporate this type of writing into their classes. Research examining the effect of teaching informal writing skills might further inform curriculum developers the most effective course assignments to teach these skills. Informal writing helps students learn course content by encouraging active thought and synthesis of knowledge (Moore, 1994). Informal writing activities can benefit both the students and the faculty member by stimulating discussion, clarifying key points and allowing exploration of new ideas in a less threatening way than through formal assignments (Moore, 1994).

Further research should include the assessment quality itself, perhaps determining if faculty members feel they are actually assessing writing skills, or instead, what the students is attempting to relate in the subject of the assessment. Additionally, it may be informative to contrast the rubric scale used in the WAC assessment to a more subjective report from faculty members about each student's ability to communicate professionally. Alumni survey has not been generated by this online university which is strongly suggested for content revision in course work applied to applicable written skills related to specific business disciplines.

\section{CONCLUSION}

America is faced with declining communication and writing skills in higher education institutions and in the workplace. This is due, in part, to education's acceptance of the lack of communication skills in college graduates, in addition to the explosion of college applications as a result of a declining economy and an increase in non-traditional student populations. Higher education institutions may lose credibility for not preparing graduates to successfully enter the workforce. As a result, businesses must spend their resources to train a workforce that should have acquired their skills in the college classroom. This study will judge the effectiveness of Writing across the Curriculum in improving the mastery of writing skills in graduating students.

\section{AUTHOR INFORMATION}

Heather Dana, an Academic Department Chair from Kaplan University, has been involved in online learning since 2005. She has taught adjunct courses for University of Phoenix before moving to Kaplan University in 2009 where began teaching Introduction to Finance as an adjunct. She soon accepted a full time position as the Department Chair for the Finance and Economics Division in the School of Business and Management. E-mail: hdana@kaplan.edu

Carol Hancock is a full-time graduate instructor in the Kaplan School of Business. Carol has taught since 2002 in five universities, with experience in both online and on ground instruction. Until 2005, she owned and operated four businesses, all that have subsequently been sold. Carol received her Doctorate in Business Administration (DBA) from the University of Phoenix, and her MBA from the University of the Pacific. E-mail: chancock@kaplan.edu

JoDee Phillips is an Adjunct Instructor with Kaplan University in the School of Business and Management. She was formally the Assistant Dean of Curriculum and Academic Department Chair with Kaplan University. She has been involved teaching online and assessing and creating curriculum for five years. JoDee's credentials are an MBA from Marylhurst University and a doctoral candidate from Northcentral University, completing her PhD in Business with an emphasis in Marketing. E-mail: jphillips@kaplan.edu 


\section{REFERENCES}

1. Betts, S. C., \& McCarthy, A. (2010). The professional writing initiative: Providing support for business students. Allied Academies International Conference: Proceedings of the Academy of Educational Leadership (AEL), 15(1), 2-6. Retrieved from EBSCOhost.

2. Bosley, D. (n.d.). Major trends facing North Carolina: implications for our state and the University of North Carolina. Manuscript submitted for publication, Center for Writing, Language, and Literacy, North Carolina State, Charlotte, NC. Retrieved from http://www.theplainlanguagegroup.com/assets/pdfs/The\%20Impact.pdf

3. $\quad$ Field, A. (2009) Discovering statistics using SPSS. Los Angeles: Sage.

4. Higher education at a crossroads. (2010). Informally published manuscript, Apollo Group,

5. Hoyt, J. E., Allred, E. R., \& Hunt, R. (2010). Implementing Writing Assessment in a Degree Completion Program: Key Issues and Lessons Learned. Journal of Continuing Higher Education, 58(1), 19-30. doi:10.1080/07377360903244299

6. Jameson, D. A. (2007). Literacy in decline: Untangling the evidence. Business Communication Quarterly, 70(1), 16-33.

7. Kelly, M. (2010). Writing Across the Curriculum: The Importance of Integrating Writing in All Subjects. Retrieved from About.com

8. Moore, R. (1994). Writing to learn biology: Let's stop neglecting the tool that works best. Journal of College Science Teaching 23: 289-295.

9. Osborne, J., Christensen, W., \& Gunter, J. (April 2001). Educational psychology from a statistician's perspective: A review of the power and goodness of educational psychology research. Paper presented at the annual meeting of the American Educational Research Association, Seattle, WA.

10. Pedhazur, E. J. (1997). Multiple Regression in Behavioral Research (3rd ed.). Orlando, FL: Harcourt Brace.

11. Quible, Z. K., \& Griffin, F. (2007). Are Writing Deficiencies Creating a Lost Generation of Business Writers?. Journal of Education for Business, 83(1), 32-36.

12. Ramey, S., VandeVusse, L., \& Gosline, M. (2007). Using a Written Communication Rubric to Improve Students' Writing. International Journal of Learning, 13(10), 67-74. 